\title{
Reliability and Life Prediction Algorithms of Insulated Cables Based on Wireless Network Communication
}

\author{
Jianyu Sun $\mathbb{D}^{1,}{ }^{1,2}$ Zhonghua Ni, $^{1}$ and Yanxin Liu ${ }^{1,2}$ \\ ${ }^{1}$ Mechanical Engineering School, Southeast University, Nanjing, Jiangsu 211189, China \\ ${ }^{2}$ Zhongli Science and Technology Group Co., Ltd., Suzhou, Jiangsu 215000, China \\ Correspondence should be addressed to Jianyu Sun; 230188150@seu.edu.cn
}

Received 24 December 2021; Revised 17 January 2022; Accepted 20 January 2022; Published 12 February 2022

Academic Editor: Alireza Souri

Copyright (c) 2022 Jianyu Sun et al. This is an open access article distributed under the Creative Commons Attribution License, which permits unrestricted use, distribution, and reproduction in any medium, provided the original work is properly cited.

Since the size of the power system is getting larger, the power of the transmission and electrical power generation also increase, and the safety operation of the transmission and electrical power is becoming more and more important. This article is intended to study algorithm for reliability and life prediction based on wireless network communication. This paper first studies the energy consumption of wireless network communication, analyzes the maximization of network life, and then evaluates the thermal aging characteristics and life of XLPE cable insulation based on wireless communication. Through model establishment and analysis, when the reliability is below $50 \%$, the reliability of the cable is basically not guaranteed. It is necessary to formulate an update and replacement plan to ensure the safe and stable operation of the power grid.

\section{Introduction}

Electricity is the heart of the coal industry. Only a good power supply environment and reliable power quality can lead the strong development of the coal industry. For load transmission, good cable quality is of great significance for ensuring power quality and safe production. Among them, the long service life of the cable and the efficiency of the cable are very important. Taking into account the particularity of coal mine areas, cables often run under dirty and humid conditions. According to the needs of different occasions, the cables are different; no matter the material or the site environmental, they are completely different from the cables buried in the power grid. In addition, many coal mining companies often allow cables to run at full load or even overload, which has a great impact on the remaining working life of the cable. These special effects make the cable generally unable to reach its normal service life. This paper firstly studies the energy consumption of wireless network communication, analyzes the network life maximization problem model, and performs curve fitting on the aging life of the insulated cable. At the same time, the building model of the reliability of the insulated cable is given, and then the thermal aging characteristics and life of the XLPE cable insulation material are evaluated according to wireless communication, and the insulation state of the XLPE cable is evaluated and predicted and reliability is evaluated.

In order to detect the occurrence of cable defects early and ensure the safe operation of the cable, it is necessary to determine the reliability of the cable and obtain the reliability of the cable at different times so as to determine the best time for cable maintenance and maintenance. Minimizing grid failures from a "macroscopic" perspective is of great significance for ensuring the safe, stable, and reliable operation of the power system.

According to the research progress at home and abroad, different scholars have also made corresponding investigations in wireless network communication and cables. Yasui et al. investigated the use of insulated cable-type down conductors as lightning protection measures for these facilities. The study found that the overvoltage caused by the lightning current in the cable can be assessed by using the lightning current reflection of the public grounding system. In addition, the overvoltage value can be estimated by the steepness of the lightning current, the surge impedance and speed of the cable, and the length of the cable [1]. He et al. 
showed that in order to gain insight into the space charge accumulation in cable accessories, under the AC voltage of $26.1 \mathrm{kV}$ and the temperature of $103^{\circ} \mathrm{C}$ and $114^{\circ} \mathrm{C}$, the $10 \mathrm{kV}$ cross-linked polyethylene (XLPE) insulated cable sample with stress cone was subjected to accelerated aging; the space charge distribution in the cable insulation layer was tested in different aging stages. The research provides insights into the important role of semiconductors in the accumulation of electrical charges in cable accessories, which will help to optimize and extend the life of cable accessories [2]. Ohki and Hirai studied how the fault location ability depends on the type, structure, and insulation material of the cable. For the location of the location heated by the heater, the cable insulated with PVC provides higher signal strength than the cable insulated with XLPO [3]. Du et al. proposed advanced materials with good thermal and electrical properties to improve the performance of electric vehicle charging cables. The test results show that modified EPDM insulation materials have good electrical and mechanical properties. In addition, the calculated theoretical current carrying capacity of the cable shows an improvement, and the use of high TC insulation and sheath seems to have great benefits in reducing the temperature of the EV charging cable and increasing the current carrying capacity [4]. Parise et al. discussed a simplified model of a low-voltage (LV) cable system with one and two time constants to evaluate cable temperature behavior and the impact of environmental and installation conditions. In addition, a device for calculating the "life loss hours" of low-voltage power cables for main/ critical circuits is proposed [5]. Callender et al. simulate the discharge by changing the surface charge density at the boundary of the gap using a logistic function distribution then use this model to study the influence of single-phase energization on the partial discharge activity in the threephase PILC cable joints. The model can describe the measured values obtained from the high-voltage equipment in operation [6]. However, these scholars did not combine wireless network communication to predict and analyze the reliability and life of insulated cables.

The innovations of this paper are mainly reflected in the following: (1) Research on the energy consumption of wireless communication networks, and propose a model for maximizing network lifetime. (2) At the same time, curve fitting was performed on the aging life of insulated cables, and the life of XLPE insulated cables was evaluated and reliability was analyzed based on the wireless communication network.

\section{Methods on the Reliability and Life Prediction Algorithm of Insulated Cables Based on Wireless Network Communication}

\subsection{Energy Consumption of Wireless Network} Communication. The rapid development of information and communication technology has brought great convenience to people's lives [7], but with the rapid expansion of user groups, the scale of business has also grown rapidly, which has brought an increasing burden on the field of communication networks [8]. At the same time, energy consumption has gradually become an important factor restricting global economic development and environmental protection, and the information and communication industry has become one of the industries with the largest energy consumption [6]. Figure 1 shows the distribution of energy consumption in wireless communication networks [9]. It is imperative to build an energy-saving, green, and environmentally friendly communication network, and it is also an effective way to promote industry growth and promote the sustainable development of global energy [10].

Before exploring the power allocation of wireless network communication, we must first understand the wireless network architecture, pay attention to the high power consumption part, and optimize the energy-saving methods in a targeted manner to achieve the best energy-saving effect [11].

Although the wireless communication system has undergone many major upgrades from $1 \mathrm{G}$ to $4 \mathrm{G}$ systems, with the introduction of new technologies such as smart antennas and more investment and productivity, the systems are still similar. It can be divided into three main components of mobile terminal, network access, and network, as shown in Figure 2. Among them, the mobile terminal is a mobile user, that is, terminal applications such as mobile phones and computers; the access network has a variety of transmission applications such as business conference catalogs and user network interfaces and is responsible for connecting users to the business network segment. The wireless access network is located between the base station and the user and moves the wireless user to the switch; the core network connects to different access networks and is responsible for connecting and managing users and the data transmission of the backend network [12]. Obviously, the entire source power of the wireless communication network occurs in three parts: the end user, the access network, and the main network.

At the same time, when planning the overall energysaving process, three aspects can be planned: equipmentlevel energy-saving, link energy-saving, and network energy-saving [13]. Equipment-level energy-saving mainly includes measures such as improving power amplifier efficiency, base station power management, and equipment dispersion; link-level energy-saving mainly includes measures such as reducing overhead and control signals, intermittent transmission, and base station idle; network-level energy-saving includes measures such as network deployment and network management [14].

\subsection{Data Processing and Aging Life Curve Fitting of Insulated Cables}

2.2.1. Data Processing. According to IEEE standards, the life of solid insulating materials obeys the two-parameter Weibull distribution [15]. Usually, the failure time when the failure probability is $64.1 \%$ is used as the aging life of the test piece. The Weibull division method is used for data processing, and the least square analysis method and MATLAB graphical method are used to obtain the Weibull measurement value. 


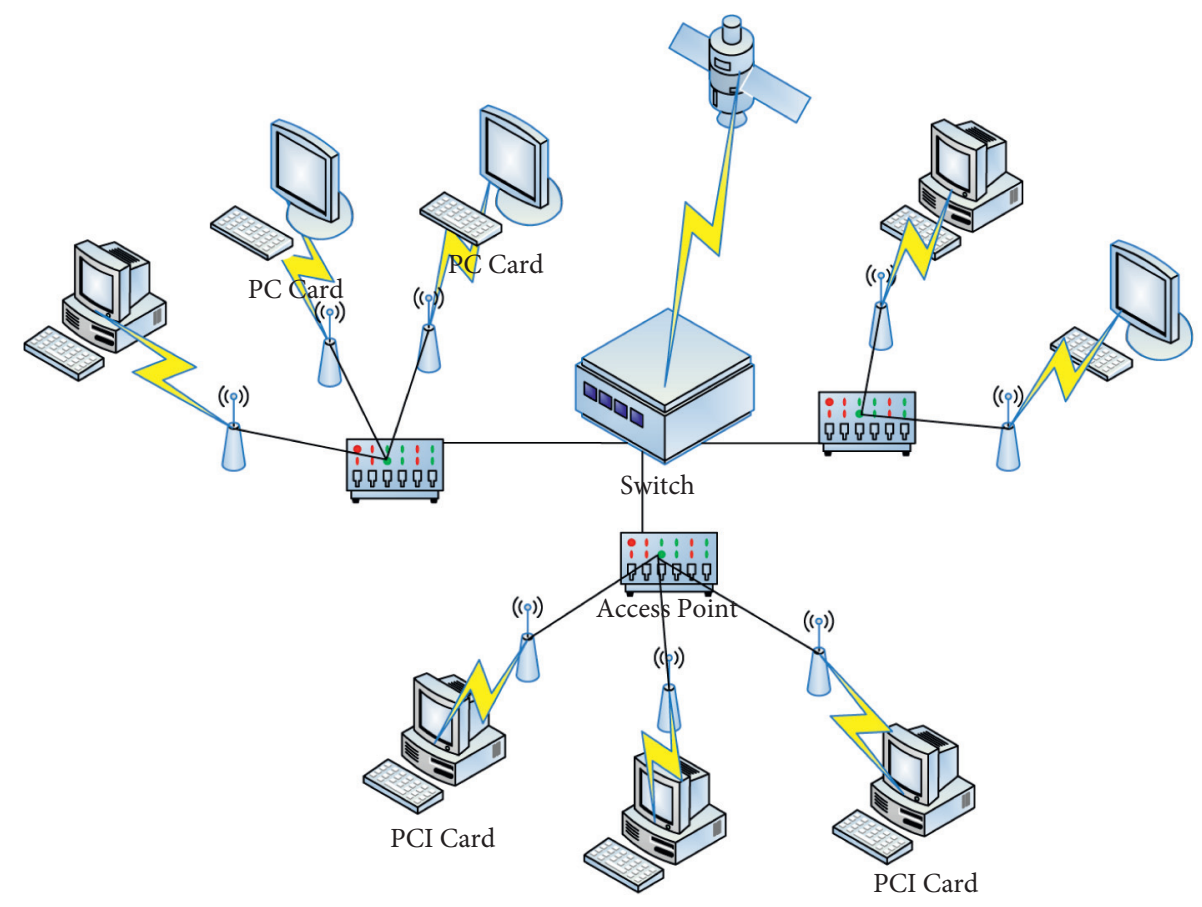

Figure 1: Distribution of energy consumption in wireless communication networks.

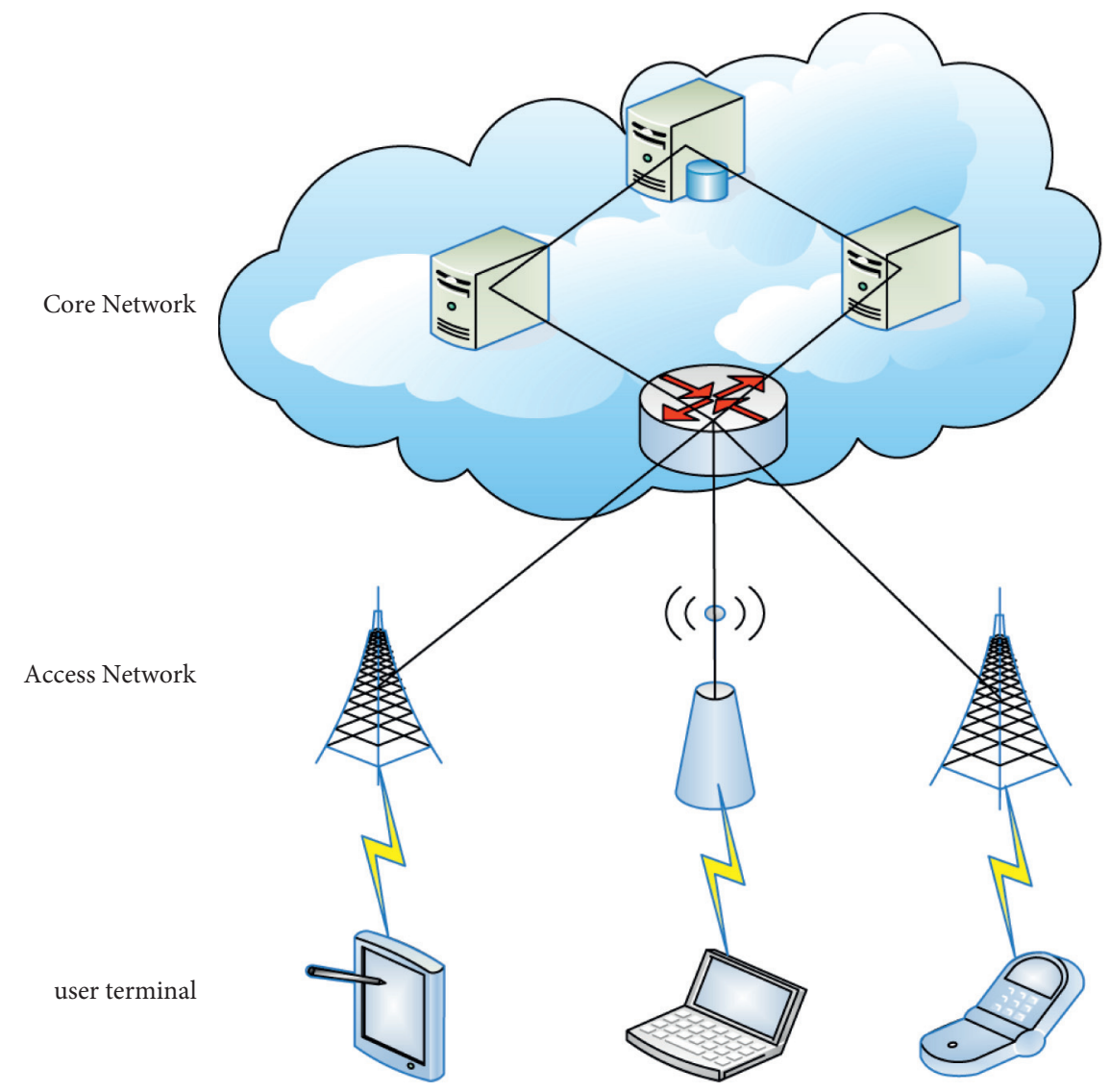

Figure 2: Wireless communication system structure. 
The Weibull two-parameter distribution equation is shown below, where $u_{h} \geq 0$ :

$$
R\left(u_{h}\right)=1-\omega^{-(u / \varphi)^{\sigma}} .
$$

Arrange the failure time in ascending order, and the cumulative probability of the $h$ th value can be approximated by the following formula:

$$
R\left(u_{h}\right)=\frac{h}{m+1},
$$

where $n$ is the total number of samples.

For the calculation of Weibull parameters, the following methods are used for comparison.

(1) Least Squares Regression Analysis Calculation Method. Arrange the Weibull two-parameter equation:

$$
\omega^{-(u / \varphi)^{\sigma}}=1-R\left(u_{h}\right)
$$

Take the logarithm of both sides of the formula and sort out the formula

$$
\left(\frac{u}{\varphi}\right)^{\sigma}=\operatorname{In}\left(\frac{1}{\left(1-R\left(u_{h}\right)\right)}\right) .
$$

Take the logarithm of both sides again and sort out the formula

$$
\operatorname{Inu}=\frac{1}{\sigma} \operatorname{In} \operatorname{In}\left(\frac{1}{\left(1-R\left(u_{h}\right)\right)}\right)+\operatorname{In} \varphi .
$$

Finally, the linearized formula is obtained:

$$
f_{h}=\frac{1}{\sigma} k_{h}+\vartheta
$$

For the linearized Weibull formula, there are many related calculation methods. This article uses the most classic least squares regression analysis method as follows:

$$
D\left(\frac{f}{K_{h}}\right)=\frac{1}{\sigma} k_{h}+\vartheta \text {. }
$$

In

$$
\begin{aligned}
& \frac{1}{\sigma}=\frac{m \sum k_{h} f_{h}-\sum k_{h} \sum f_{h}}{m \sum k_{h}^{2}-\left(\sum k_{h}\right)^{2}}, \\
& \vartheta=\frac{\sum k_{h} \sum k_{h} f_{h}-\sum k_{h}^{2} \sum f_{h}}{m \sum k_{h}^{2}-\left(\sum k_{h}\right)^{2}}=\operatorname{In}(\varphi) .
\end{aligned}
$$

(2) Based on MATLAB Graphic Method. Weibull's solution has two automated methods, namely, graphical scale method and iterative statistical method. The graphical method is to track the cumulative error probability percentage of the Weibull parameter on the graph paper-the error time point-and draw a straight line following the trend change. This method is not only inefficient, but also has large errors. Therefore, according to the principle of the graph estimation method, MATLAB graphs are used to process data [16]. According to different voltage levels, through polynomial line compatibility matching the data of the corresponding reactor failure probability and failure time, the performance signals corresponding to different voltage levels are obtained.

2.2.2. Fitting of the Aging Life Curve. The electrical aging test obtains the aging life data of the electrode with a diameter of $2 \mathrm{~mm}$ and the oleoresin insulation under four aging voltages. In the test, the number of samples for each electrode system under each test voltage is three. Arrange from small to large, calculate according to Weibull summation probability formula, get the failure time of each group of two electrode processors under each group's summation probability. The data distribution is shown in Table 1.

Use MATLAB graphical method to process the data, according to different voltage levels to match the big row data in the total failure probability table and the time failure table, and get the performance signals corresponding to different voltage levels [17].

In the aging life assessment method, we believe that the aging effect of aging factors on epoxy protective materials is consistent with the antiaging energy model. Among them, epoxy resin is a kind of high-molecular polymer, which refers to the general name of a class of polymers containing two or more epoxy groups in the molecule. It is the polycondensation product of epichlorohydrin and bisphenol A or polyol. Therefore, we use a representative energy law model to match the aging life model, and the data has been replaced with a power recovery model. And use the Curve Fitting Tool application in MATLAB to adjust the fit to suit the service life of the $2 \mathrm{~mm}$ electric shock absorber, as shown in Figure 3.

The expression is as follows:

$$
M=1.498 * 10^{15} * Q^{-9.5923} .
$$

The goodness of fit $P^{2}$ is 0.9798 .

2.3. Network Lifetime Maximization Problem Model. In many types of wireless sensor networks, the power of sensor components is mainly used for listening, processing, transmitting, and receiving data [18]. Generally speaking, the power consumption of sending and receiving data streams accounts for most of the total energy consumption. Therefore, this article ignores the power consumption of sensors and data processing and only considers the power consumption of the communication module in the sensor node. The energy consumption per unit time of sensor node $t$ can be expressed as follows:

$$
q_{t}=\sum_{k \in \gamma_{\text {in }}(t)} \sum_{t \in T(k)} q_{t, k}^{a} d_{t}+\sum_{k \in \gamma_{\text {out }}(t)} \sum_{t \in T(k)} q_{t, k}^{b} d_{t^{\prime}} .
$$

Here, $q_{t, k}^{a}$ represents the energy consumption of node $t$ receiving unit data from link $k$. In this article, it is assumed that its value is constant; $q_{t, k}^{a}$ represents the energy consumption of node $t$ sending unit data through link $k$, and its value can be calculated by the following expression: 
TABLE 1: Cumulative probability and failure schedule.

\begin{tabular}{|c|c|c|c|c|}
\hline Cumulative probability & Aging voltage (KV) & 0.25 & 0.5 & 0.75 \\
\hline \multirow{4}{*}{ Unequal diameter electrode failure time $(\mathrm{h})$} & 23 & 1858 & 1922 & 1951 \\
\hline & 25 & 803 & 813 & 826 \\
\hline & 41 & 201 & 213 & 218 \\
\hline & 39 & 20 & 24 & 27 \\
\hline \multirow{4}{*}{ Failure time of rod-plate electrode $(\mathrm{h})$} & 21 & 1601 & 1632 & 1641 \\
\hline & 25 & 758 & 785 & 809 \\
\hline & 31 & 79 & 89 & 101 \\
\hline & 29 & 26.1 & 27.9 & 30.1 \\
\hline
\end{tabular}
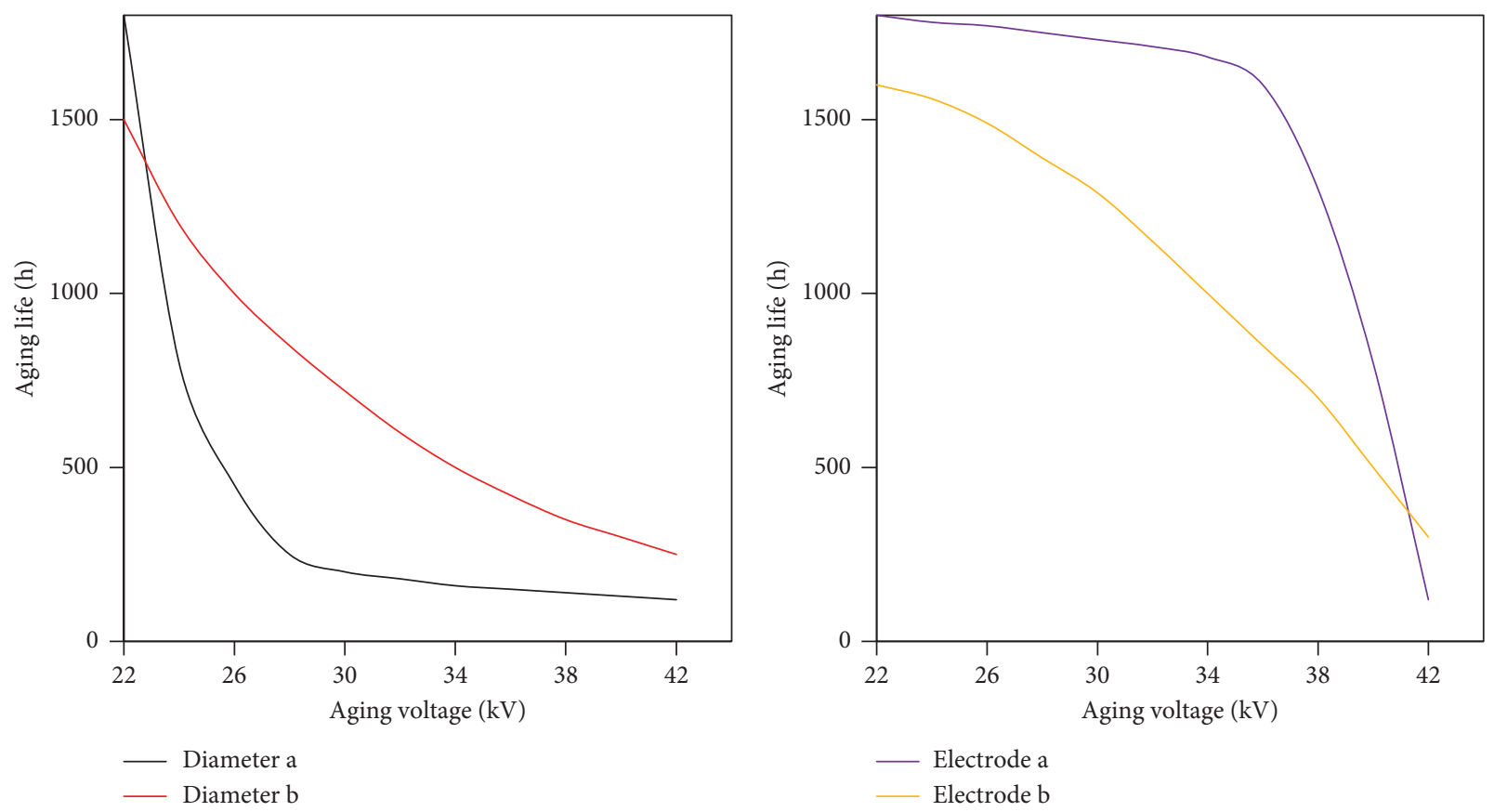

Figure 3: Aging life curve.

$$
q_{t, k}^{a}=\varphi+\delta m_{t, k}^{\theta}
$$

Here, $\varphi$ and $\delta$ represent constants related to physical layer functions and environmental factors; $m_{t, k}$ represents the length of the logical link $k$, and $\theta$ represents the path loss constant $(2 \leq \theta \leq 4)$.

Assuming that the initial energy of the sensor node is represented by $e_{t}$, the lifetime of the node $t$ can be expressed as follows:

$$
B_{t}=\frac{e_{t}}{q_{t}}
$$

In this article, the life cycle of the network is defined as the life cycle of the first sensor node whose energy has been exhausted. Therefore, maximizing the network life cycle means maximizing the minimum life cycle of sensor nodes in the network. If $B$ is used to represent the lifetime of the wireless sensor network, then $B=\min _{t \in T} B_{t}$. The problem of maximizing network lifetime can be expressed as follows:

$$
\operatorname{maximizemin}_{t \in T} B_{t} \text {. }
$$

It is very difficult to solve this problem in a distributed manner because each sensor node needs to interact with all other nodes to know their power consumption [19].

The following method is used to approximate the network lifetime maximization problem [20]. Consider the utility function $f^{\varphi}(\cdot)$, which is defined as follows:

$$
f^{\varphi}(a)= \begin{cases}\log a, & \varphi=1, \\ \frac{1}{1-\varphi} a^{1-\varphi}, & \varphi>1 .\end{cases}
$$

When the utility function is shown in (17), and when $\varphi \longrightarrow \infty$, the problem of maximizing the minimum rate allocation of each source node can be achieved by maximizing the total utility [21]. The network lifetime maximization problem shown in (13) is to maximize the minimum lifetime of sensor nodes, which is similar to the problem of maximizing the minimum rate allocation of each source node [22]. Therefore, a lifetime utility function $f_{t}^{\varphi}\left(B_{t}\right)$ is introduced for each sensor node $t$, which is defined as follows: 


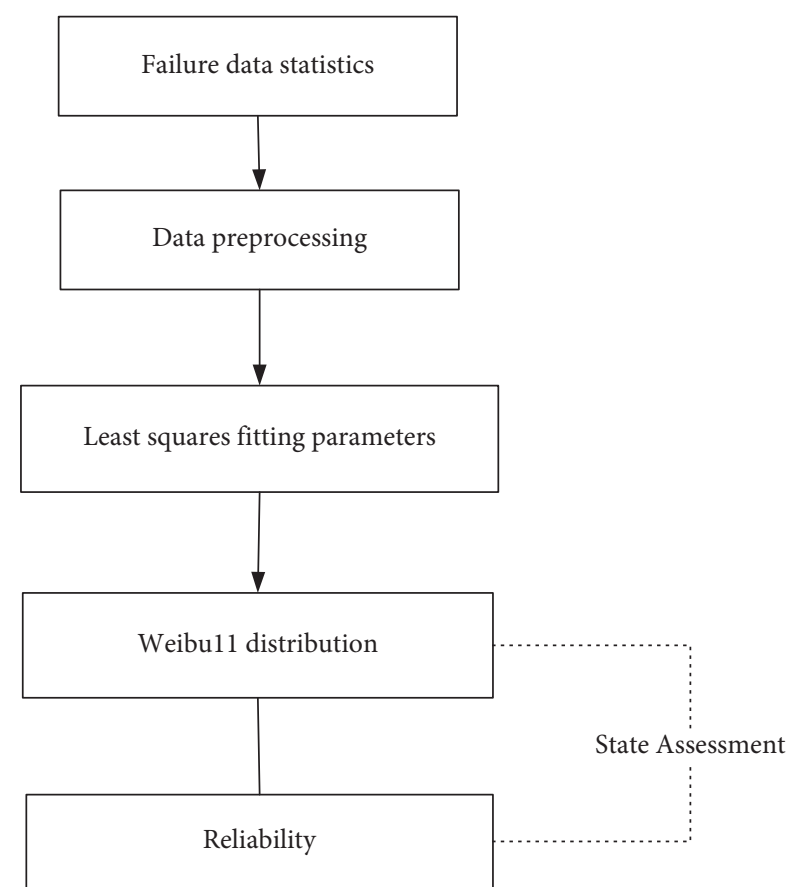

FIGURE 4: Cable reliability model.

$$
f_{t}^{\varphi}\left(B_{t}\right)=\frac{1}{1-\varphi} B_{t}^{1-\varphi} .
$$

Therefore, maximizing the network lifetime can be achieved by maximizing the total lifetime utility; namely,

$$
\operatorname{maximize} \sum_{t \in T} f_{t}^{\varphi}\left(B_{t}\right) \text {. }
$$

In order to simplify the problem, we make the following transformation and introduce a new variable: $W_{t}=1 / B_{t}$, which can be understood as the normalized energy consumption of node $t$. In summary, the problem of maximizing network lifetime is transformed into

$$
\begin{gathered}
\operatorname{maximize} \sum_{t \in T} \frac{1}{1-\varphi} W_{t}^{\varphi-1}, \\
\text { subject to } q_{t}=e_{t} z_{t}, \quad \forall t \in T .
\end{gathered}
$$

2.4. Construction of the Reliability Model of Insulated Cables. The modeling process of the insulated cable reliability model is shown in Figure 4.

The implementation steps of the model are described in words as follows:

(1) Analyze the statistical data of the fault data and obtain the statistical data that can be used for preconfiguration [23]

(2) Preprocessing of statistical data

(3) Use least squares fitting to fit the preprocessed data to find the shape parameters in Weibull

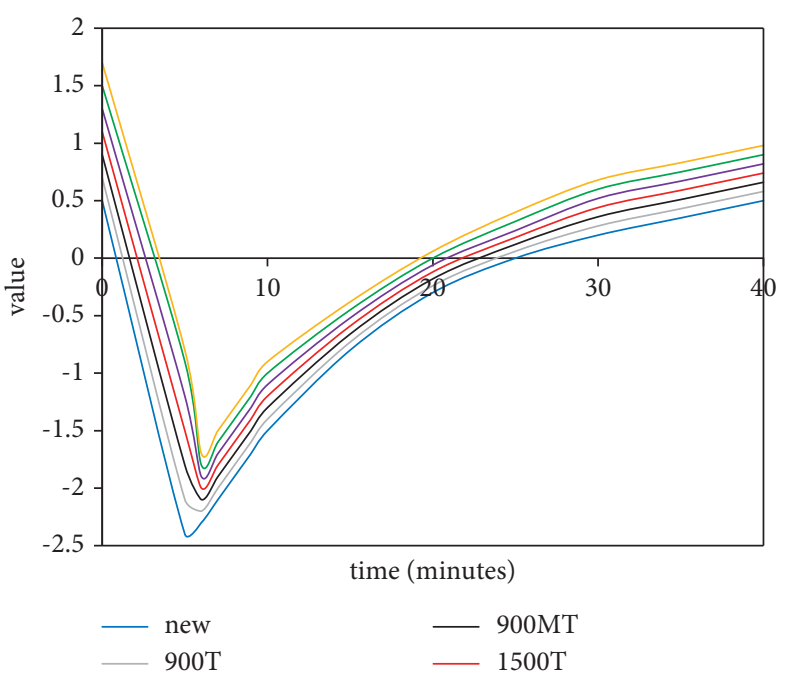

FIgURE 5: Oxidation induction period curve of samples with different aging time periods.

(4) After obtaining the shape parameters of the Weibull distribution, the Weibull distribution is obtained

(5) According to the Weibull distribution, the reliability is obtained, and combined with the state evaluation result, the final reliability evaluation result is obtained [24]

\section{Experimental Results on the Reliability and Life Prediction Algorithm of Insulated Cables Based on Wireless Network Communication}

3.1. Evaluation of Thermal Aging Characteristics and Lifespan of XLPE Cable Insulation Materials Based on Wireless Network Communication. We have studied and discussed the thermal aging parameters of cables, such as aging time and temperature. At the same time, the cables made of crosslinked polyethylene (XLPE) polymer materials are used as samples for analysis and research. In order to analyze the influence of different aging time on the OIT-induced oxidation time of the samples under pure heat conditions and the approximate heat in the aging perfusion, a total of 7 groups of samples were tested for the oxidation induction period. The test results of 7 groups of samples are shown in Figure 5 .

The test results show that the induction time of the crosslinked polyethylene sample is very short after 2100 hours of heat shrinkage under the composite aging heat. The induction time of the new cross-linked polyethylene sample is 21 minutes. The induction time of the cross-linked polyethylene sample plus the aging time is longer than the shortterm aging induction time, indicating that the average aging heat transfer rate is significant and the induction time is shorter. As the aging degree of the sample increases, the oxidation induction time decreases significantly. XLPE is a high-molecular polymer, which will decompose to produce a large number of free radicals in the aging environment of thermal oxygen oxidation. The free radicals act as a catalyst 


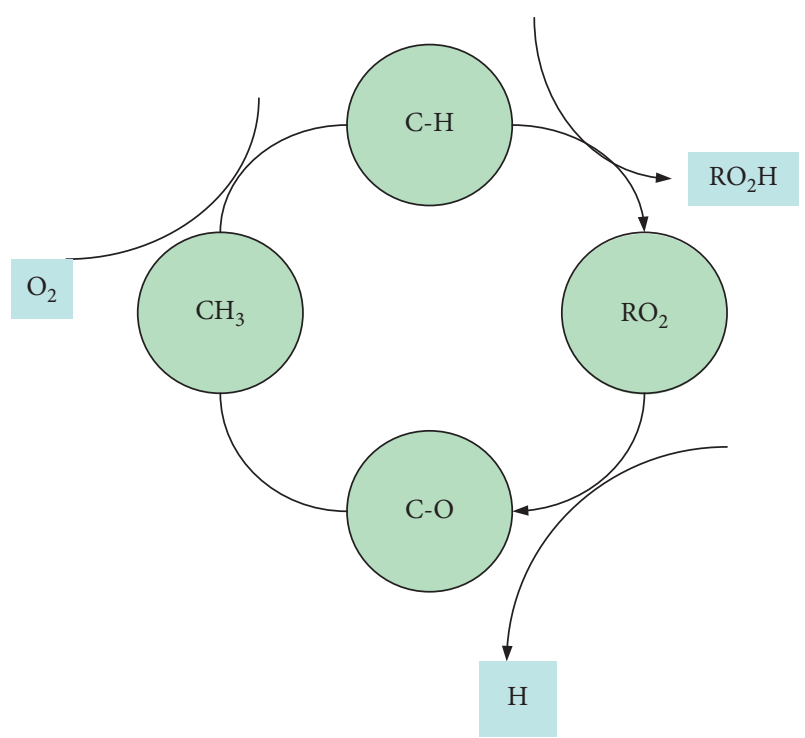

Figure 6: Aging chain reaction mechanism.

to initiate a chain reaction so that the cross-linked macromolecules are continuously decomposed, thereby reducing heat insulation. Maintain stability and oxidation resistance, thereby shortening the oxidation induction time. XLPE is a kind of high-molecular-weight polymer, which will degrade to produce a large amount of free radicals in the aging environment of hot exhalation. Free radicals act as a catalyst to produce chain reactions, often decomposing and cross-linked macromolecules, thereby reducing thermal insulation and shortening the induction time. The chain reaction principle of each stage of the aging process is shown in Figure 6.

In Figure 6, RO2 stands for peroxide radical; $\mathrm{RO} 2 \mathrm{H}$ : hydrogen peroxide radical; $\mathrm{C}=\mathrm{O}$ : carbonyl; $\mathrm{CH} 3$ : methyl; and $\mathrm{H}$ : free hydrogen.

The antioxidant in the cross-linked polyethylene cable insulation material basically absorbs the peroxide radicals in the aging chain, which can prevent it from participating in the aging and aging cycle of aging perfusion, thereby preventing the material from being damaged due to corrosion. When the temperature is high, the generation rate of free peroxide increases, the reaction rate with antioxidants accelerates, the antioxidants are digested faster, the regenerative degradation of oxidative stress increases, and the induced oxidation time is shortened.

The aging of XLPE cables can be divided into two periods: the transformation period and the thermal incubation period. Due to the presence of antioxidants in the regeneration phase, the oxidation activity is inhibited and cannot continue spontaneously. Thermal oxygen aging is a spontaneous oxidation process, which has the characteristics of free radical chain oxidation and auto-oxidation. As the thermal oxidative aging process progresses, antioxidants are consumed. With the continuous consumption of antioxidants, the bonds of cross-linked polyethylene macromolecules are broken, some of the macromolecules decompose into small molecules, and the small molecules contact each other and crystallize again.
In the thermal oxidation aging stage, antioxidants mainly capture peroxide radicals in the aging reaction chain so that they no longer participate in the synthetic aging cycle caused by thermal oxidation and vibration oxidation, and at the same time prevent the material from undergoing thermodynamic oxidative decomposition. In the thermal aging stage of oxygen, the free radicals of the molecular chain react with oxygen to form peroxides, which are decomposed into free radicals and form free radicals with oxygen atoms. The production of peroxide increases, and the peroxide activity is high, and it can interact with atoms, molecules, or free radicals. The influx of molecular structure into the material leads to further reduction of long chains and formation of molecular products. Therefore, the corrosion behavior of the excitation material in the XLPE cable is improved and the induction time is reduced.

Due to the aging process, the heat and insulation of the insulating material will be reduced to a certain extent. Therefore, antiaging protection is characterized by power shortages and frequent changes in material life. The aging range is between mild and severe. Assuming that the protective activity is between $10 \%$ and $50 \%$, each aging is calculated by reducing the parameter by $10 \%$. Among them, Table 2 shows the changes in the aging temperature field of the cable main insulation.

According to comparative analysis, the fiber loss is $50 \%$, and the highest temperature in the fiber reaches $66.96^{\circ} \mathrm{C}$, but the average diameter between the two layers and the temperature between the layers do not change. At the beginning of the loss (loss 10\%-20\%), the copper core temperature rises slightly (0.5\%), and as the loss increases (loss 30\%-50\%), the copper core temperature rises significantly (4\%). It shows that the decrease of insulation performance is nonlinearly related to the increase of temperature. Compared with conventional work, the electric field strength is much higher than the separation electric field. This is because the insulation activity and temperature of the cable will gradually decrease during the aging process, and the decrease of the insulation activity will aggravate the aging of the cable, which is a vicious circle. Therefore, when the cable ages to a certain extent, the cable needs to be replaced; otherwise, the insulation will break and cause greater harm. Figure 7 shows the aging life diagram of cables at different temperatures and different end-point levels. It can be seen from the figure that at $70^{\circ} \mathrm{C}$ and $40 \%$ of the end-point level, the aging strength of the cable is much stronger than that of other temperature levels. Through the establishment and analysis of the model, when the XLPE insulation material simulates the typical $0.5 \mathrm{~m} / \mathrm{s} 2$ vibration acceleration in the actual working cable environment under the working temperature $\left(90^{\circ} \mathrm{C}\right)$ environment, its expected life is 27.1 years.

In order to determine the influence of different impurity content on the aging of the circuit, $0.5 \mathrm{~mm}$ impurities are removed each time, and the software analyzes the temperature and light intensity, as shown in Table 3.

When there are impurities in the cable, there will be slight changes according to the location of the impurities, the highest temperature inside the cable, the average temperature between the two phases, and the temperature of the 
TABLE 2: Changes in the temperature field of cable main insulation aging.

\begin{tabular}{lcccc}
\hline $\begin{array}{l}\text { Cable insulation } \\
\text { performance loss }\end{array}$ & $\begin{array}{c}\text { The highest temperature } \\
\text { inside the cable }\left({ }^{\circ} \mathrm{C}\right)\end{array}$ & $\begin{array}{c}\text { Average temperature between } \\
\text { two phases }\left({ }^{\circ} \mathrm{C}\right)\end{array}$ & $\begin{array}{c}\text { Filling material } \\
\text { temperature }\left({ }^{\circ} \mathrm{C}\right)\end{array}$ & $\begin{array}{c}\text { The highest electric field } \\
\text { strength inside the cable }(\mathrm{mV} / \mathrm{m})\end{array}$ \\
\hline Normal operations & 52.01 & 46.95 & 44.01 & 1.1398 \\
Loss 10\% & 54.02 & 47.89 & 43.98 & 1.1985 \\
Loss 20\% & 55.98 & 49.01 & 44.29 & 1.4698 \\
Loss 30\% & 59.03 & 49.58 & 44.39 & 1.8023 \\
Loss 40\% & 62.97 & 51.08 & 45.03 & 2.0035 \\
Loss 50\% & 66.96 & 52.02 & 45.02 & 2.1502 \\
\hline
\end{tabular}
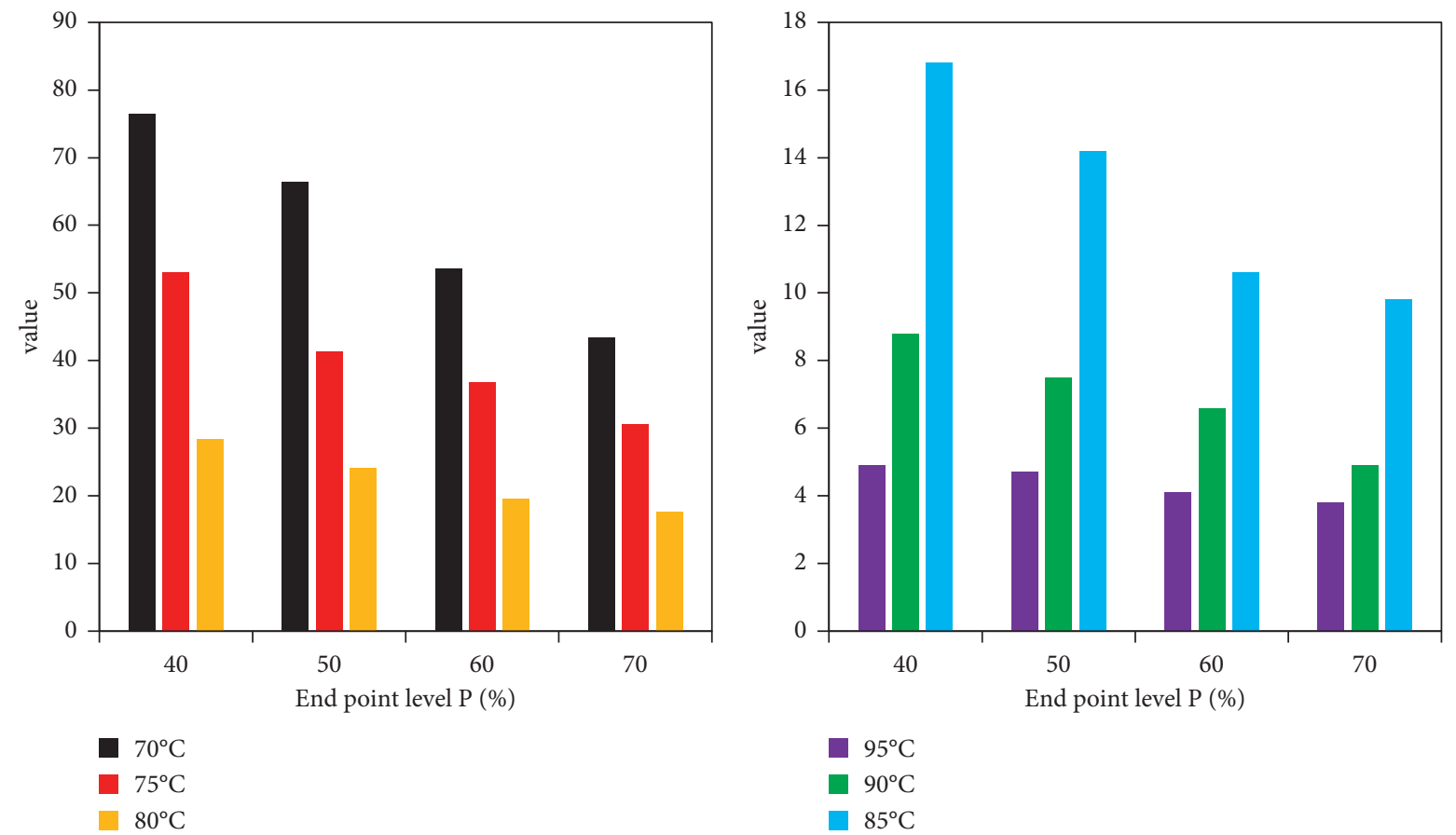

FIGURE 7: Cable ageing life under different temperatures and different end-point levels.

TABLe 3: Thermal field and electric field distribution table of impurity in cables.

\begin{tabular}{lcccc}
\hline $\begin{array}{l}\text { Distance between impurity } \\
\text { and conductor edge }(\mathrm{mm})\end{array}$ & $\begin{array}{c}\text { The highest temperature } \\
\text { inside the cable }\left({ }^{\circ} \mathrm{C}\right)\end{array}$ & $\begin{array}{c}\text { Average temperature } \\
\text { between two phases }\left({ }^{\circ} \mathrm{C}\right)\end{array}$ & $\begin{array}{c}\text { Filling material } \\
\text { temperature }\left({ }^{\circ} \mathrm{C}\right)\end{array}$ & $\begin{array}{c}\text { Electric field distribution of } \\
\text { cable impurities }(\mathrm{mV} / \mathrm{m})\end{array}$ \\
\hline 1.5 & 51.59 & 46.83 & 42.71 & 4.98 \\
2 & 51.41 & 46.33 & 42.89 & 4.26 \\
2.5 & 50.81 & 46.51 & 43.78 & 3.99 \\
\hline
\end{tabular}

filling material. However, the electric field where the impurity is located is very strong, and partial discharge is prone to occur at this time, and insulation failure will occur within a few seconds. In this case, the cable insulation completely fails, and short circuit and other faults may occur. However, this type of damage does not occur immediately after the cable is used because the insulation is poor and the efficiency value is reduced. Therefore, the presence of impurities should be avoided as much as possible.

It can be seen from Table 3 that the presence of impurities has a greater correlation with the highest internal field strength, a lower correlation with the internal temperature, and a lower correlation with the ambient temperature.
3.2. Insulation State Evaluation Prediction and Reliability Evaluation of XLPE Cables Based on Wireless Network Communication. The Weibull distribution describes the damage chain reaction based on the calculation process. It is derived from the series model and the weak link model. It can fully illustrate the impact of material defects on the life of the material, and the damage of many faults to the safety of the cable. In addition, since the current simplified curve bathtub is widely used to simulate the failure rate of power system components, this object uses bath waves to calculate reliability. The shape of the bath curve during sporadic failure and aging failure is basically the same as the Weibull distribution, so this paper evaluates the cable reliability based on the Weibull distribution. 

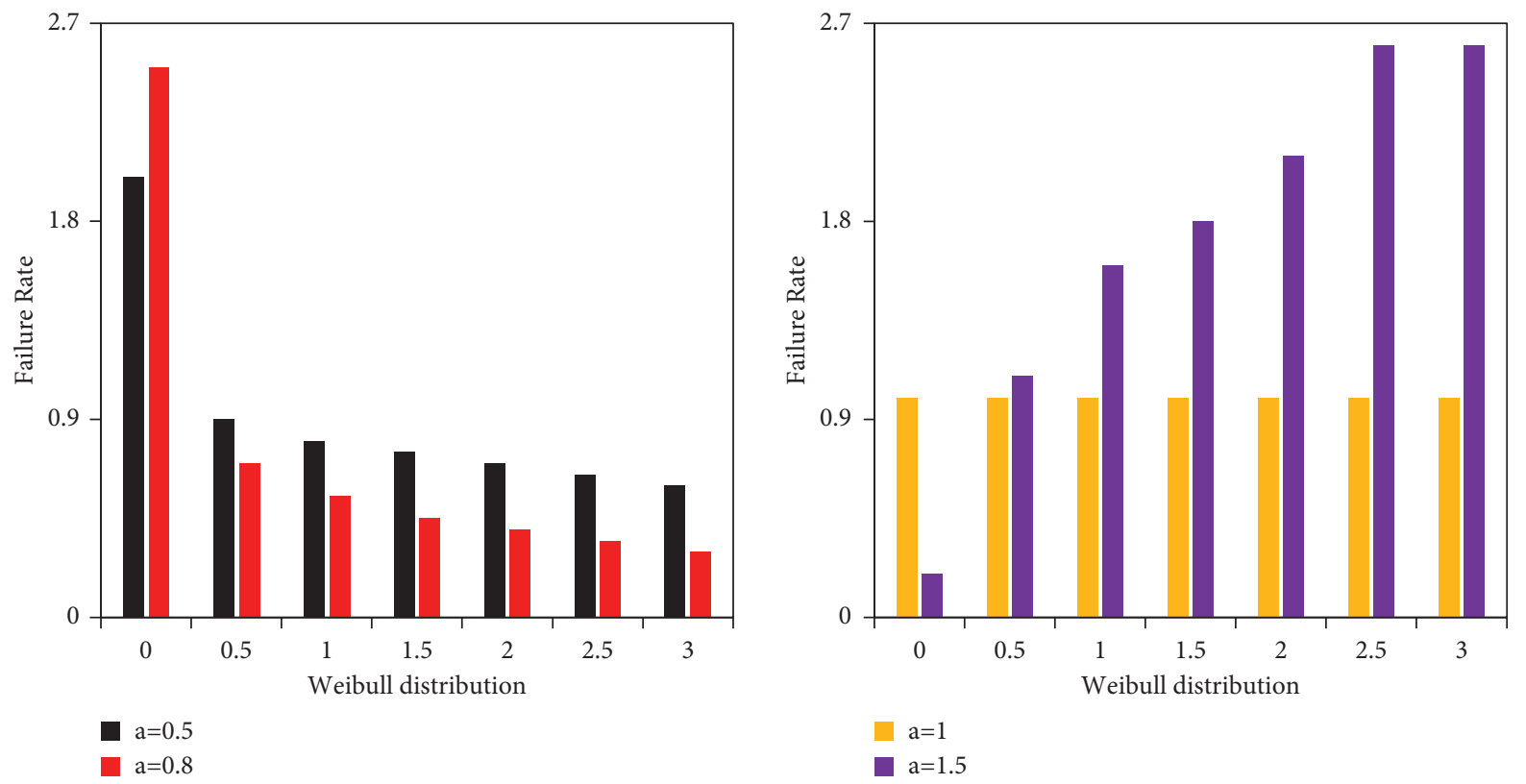

FIgURE 8: Weibull distribution failure rate.
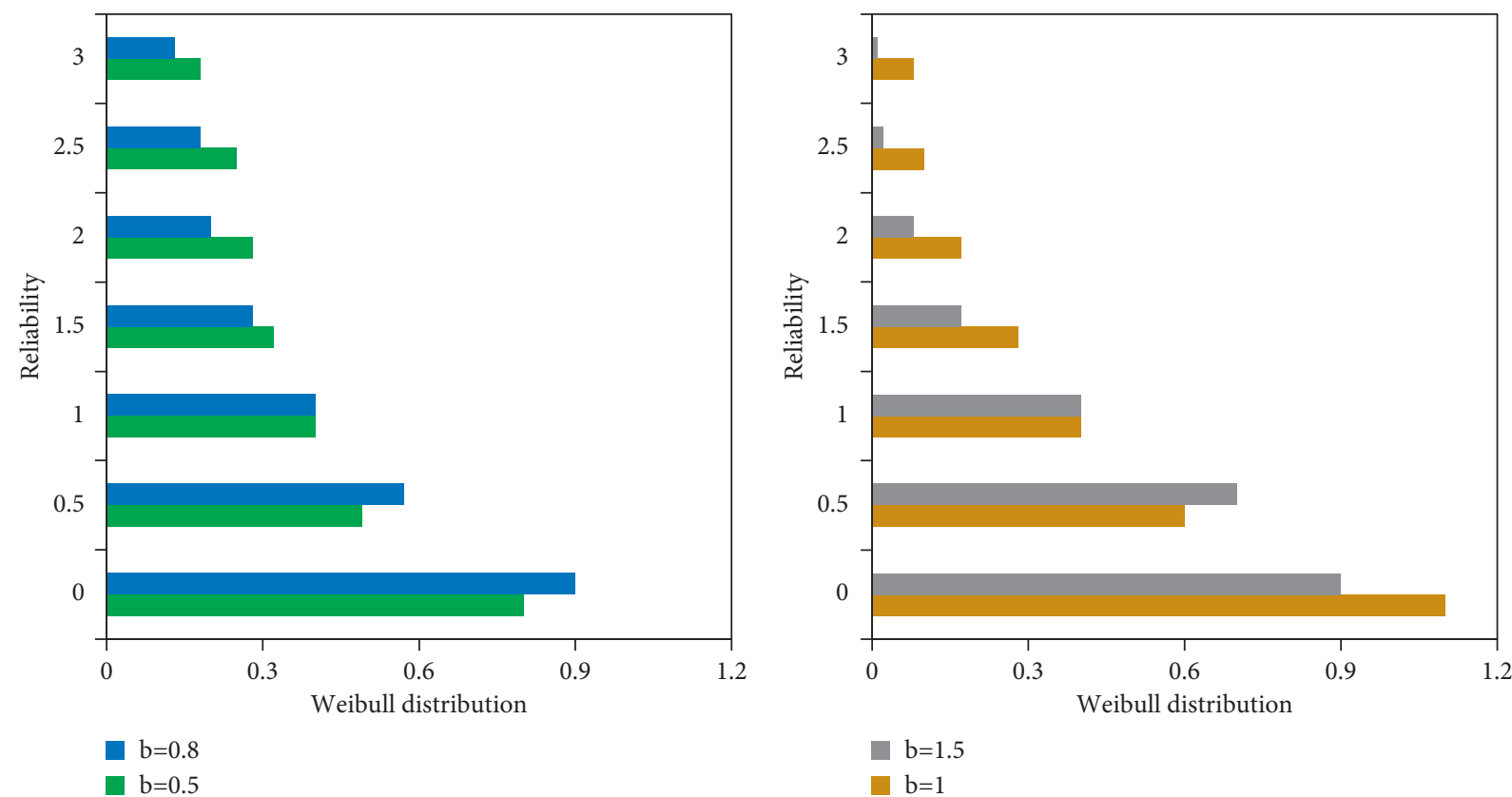

FIgure 9: The reliability of the Weibull distribution.

The Weibull distribution describes the damage chain reaction based on the calculation process. It is derived from the series model and the weak link model. It can fully demonstrate the impact of material defects on the life of the material and the corrosion of many target faults on the cable protection. Figure 8 shows the failure rate of the Weibull distribution.

Using statistical methods to deal with data line failures and calculate cable reliability is also a current and popular research guide in the era of big data. Figure 9 shows the reliability diagram of the Weibull distribution.
At the same time, it has also been observed that $80 \%$ of cable failures are caused by external damage in addition to their own reasons, and there is more than one reason for cable failure. Therefore, the probability of each independent failure cause is part of the calculation of the total failure probability of the cable.

It can be seen from Figure 10 that the cumulative failure rate of the cable follows the bathtub curve. In the first 1 to 2 years, due to early failures caused by poor production quality and improper installation, the press showed a slight downward trend; the service life was about 2 to 4 years, and 


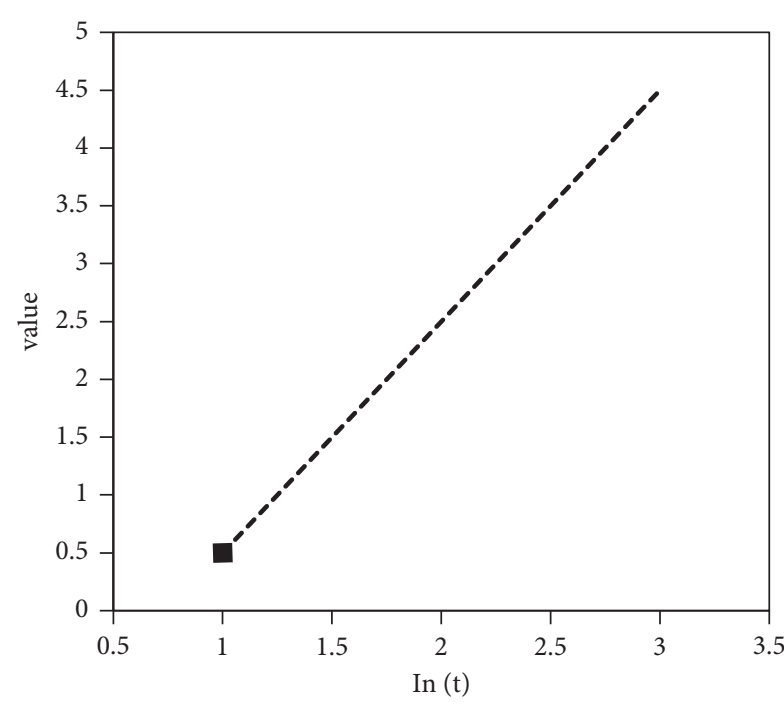

- Fit straight line

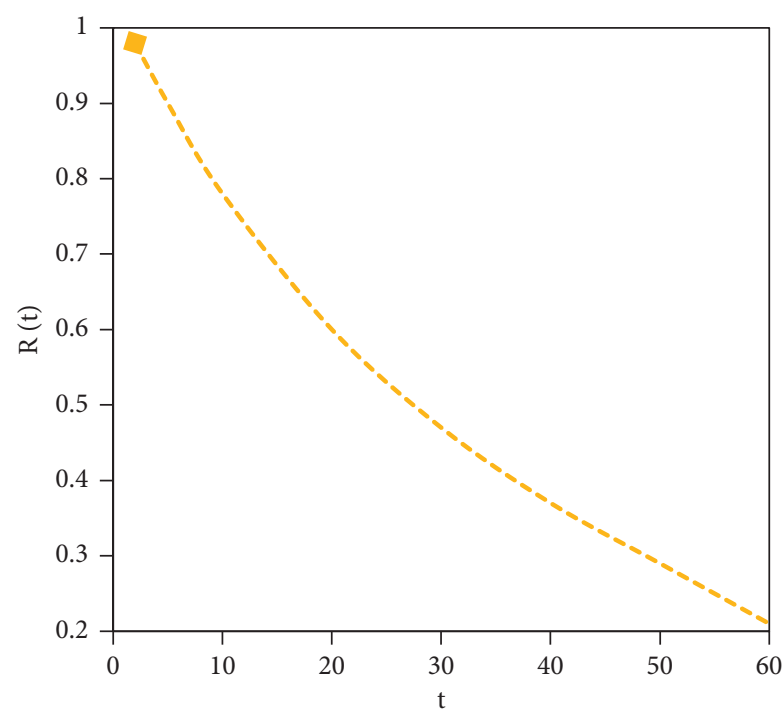

--- XLPE cable reliability

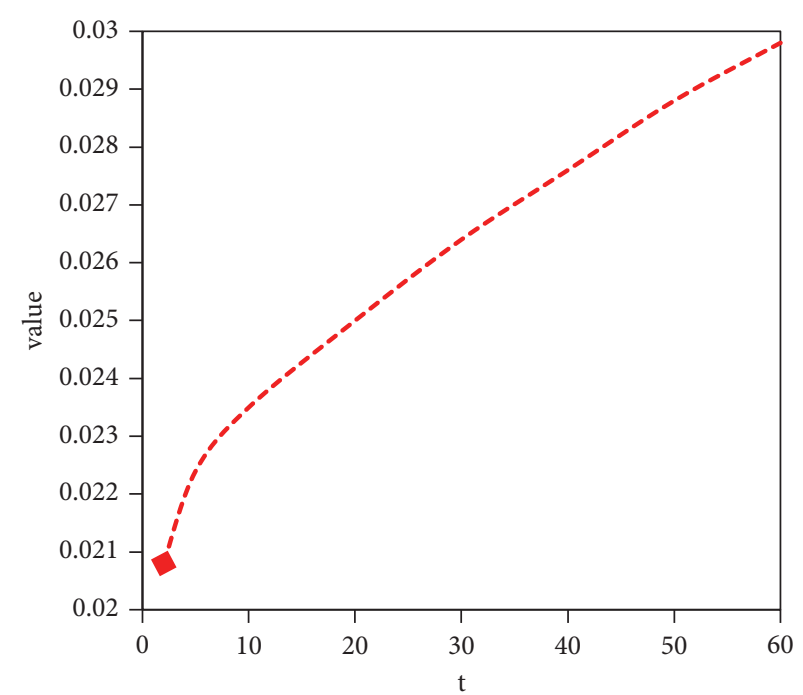

--- XLPE cable failure rate

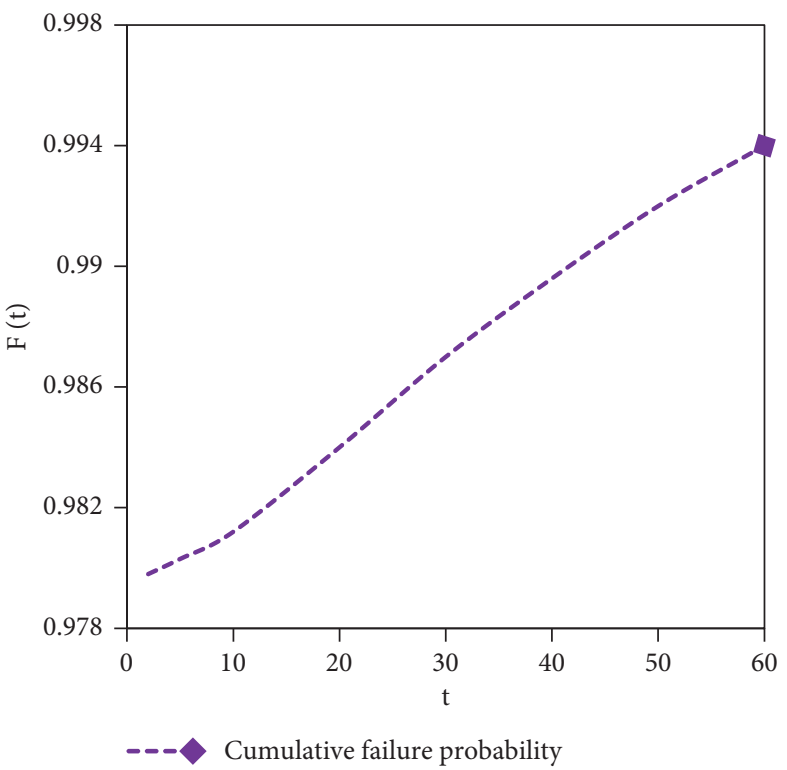

FIGURE 10: XLPE cable reliability and failure rate curve.

the probability of complete cable failure remained basically unchanged. After 4 years, the curve began to grow, and by about 30 years, the growth trend tended to be flat, which means that in about 30 years, cable maintenance activities are also going on simultaneously, avoiding an increase in the failure rate. It can be seen from the figure that the failure rate of the optical fiber increases with the increase of the operation time of the optical fiber, and the reliability decreases with the increase of the time, which is consistent with the previous analysis and data analysis of the optical fiber.

If we can get suitable working rope conditions at one time, we need to plan the working position of the rope before confirming the reliability of the working rope. From the results of line A in Table 4, the result of the reliability rating is 0.459 . The reliability obtained directly from the reliability fitting chart 10 is $82.9 \%$. At this time, it can be seen from the
TABLE 4: Reliability evaluation results.

\begin{tabular}{lcccccc}
\hline \multirow{2}{*}{ Line name } & $\mathrm{m}^{\prime}$ & \multicolumn{3}{c}{$\mathrm{m}^{\prime}(\mathrm{A})$} & $\mathrm{R}(\mathrm{t})$ & $\mathrm{R}^{\prime}(\mathrm{t})$ \\
& & $\mathrm{S}_{1}$ & $\mathrm{~S}_{2}$ & $\mathrm{~S}_{3}$ & & \\
\hline Line A & 0.990 & 0.131 & 0.561 & 0.218 & 0.829 & 0.459 \\
Line B & 0.129 & 0.121 & 0.541 & 0.220 & 0.671 & 0.361 \\
Line C & 0.089 & 0.161 & 0.549 & 0.201 & 0.601 & 0.339 \\
\hline
\end{tabular}

statistical data that line A has failed, which is obviously inconsistent with the high reliability of $82.9 \%$. After considering the status of line $\mathrm{A}$, the confidence level becomes $45.9 \%$, which is obviously more realistic. Likewise, the final result of line $B$ is more tangible. It can be seen from Figure 10 that the reliability of line B after 22 years of operation is not high, only $60.1 \%$. The statistical results show that line C ended in failure in August 2011 and November 2011. The final result of the comprehensive status assessment is $33.9 \%$, 
which is also more realistic. Therefore, it can be seen that the model has certain feasibility.

Cable reliability analysis is to evaluate the health of cables from a "macro" perspective of the power grid and can provide important guidance for relevant operation and maintenance personnel from a "macro" perspective. Therefore, the fitting of cable reliability curve can provide maintenance advice for operation and maintenance personnel. For example, when the reliability is maintained at about $80 \%$, the cable is less affected by the aging process, which can reduce the frequency of routine maintenance and prevent accidental failures such as external force impacts from causing cable failures; with the extension of the cable running time, the reliability continues to decline, and the influence of cable aging is also increasing. Once the external stress (mechanical force, heat, load, etc.) increases, the reliability will be greatly reduced. It is necessary to increase cable maintenance and control operating conditions to extend the service life of the cable. When the reliability is lower than $50 \%$, the reliability of the cable cannot be basically guaranteed, and it is necessary to formulate an update and replacement plan to ensure the safe and stable operation of the power grid.

\section{Discussion}

This model is based on wireless network communication, combined with the analysis of aging average test results, and calculates the long-term reliability of XLPE protection applications under multiple parameters. By comparing heating and aging methods, the XLPE aging test under the thermal conditions of polymerization shows the long-chain characteristics and kinetic crystal control crystal structure of the aging polymer XLPE polymer and introduces the fluidity and crystals between molecular chains. At the same time, the power grid is the main interface between the power load picker and the power system and an important guarantee for decision-making reliability and power supply quality. In the actual operation of XLPE cable, due to the local heating of the conductor caused by the working current, the cable insulation has thermal aging under high temperature conditions for a long time, resulting in various complex physical and chemical changes in the XLPE insulation. Among them, thermal aging is an important part of various aging. Thermal aging reduces the mechanical properties of XLPE cable insulation such as tensile strength and elongation at break and damages the internal microstructure of the insulation. Moreover, thermal stress and other stresses act together to accelerate the aging of cable insulation. Temperature can increase the chemical reaction rate, so the relationship between degradation rate and temperature in thermal aging is similar to the chemical reaction rate equation.

\section{Conclusions}

The cable condition is to evaluate the cable from the cable itself compared with the reliable analysis; it is to analyze the operating condition of the cable from the "micro" perspective; from the perspectives of "macro" and "micro", conduct simultaneous analysis and investigation of the operating status of the cable, as well as the relationship between cable failure and cable aging, accidental damage, and cable maintenance. Fully consider maintenance and collect cable performance more comprehensively and accurately. Provide more valuable reference for operation and maintenance personnel. For example, line A in this example, from a "macro" perspective, has $83 \%$ confidence when it runs to 8.45 years. If you consider this result alone, it can be considered that the cable will not fail; in fact, the cable has failed at this time. Comprehensive inspection of its operating status results in a reliability of $46 \%$, which is very low. Operation and maintenance personnel can formulate relevant maintenance plans accordingly. Therefore, the model proposed in this chapter comprehensively considers a variety of factors, evaluates the reliability of the cable, and helps operation and maintenance personnel propose maintenance and replacement plans in a timely manner so that the reliability of the cable meets the requirements and realizes comprehensive management. Due to the limitations of time and technology, we will further analyze and study other properties of cables in the future in order to make certain contributions to the cause of social and public safety.

\section{Data Availability}

No data were used to support this study.

\section{Conflicts of Interest}

The authors declare no conflicts of interest.

\section{References}

[1] S. Yasui, K. Sakaguchi, and T. Tsuchida, "Overvoltage in insulated-cable-type down conductor," IEEJ Transactions on Power and Energy, vol. 137, no. 11, pp. 710-716, 2017.

[2] D. He, T. Zhang, M. Ma, W. Gong, W. Wang, and Q. Li, "Research on mechanical, physicochemical and electrical properties of XLPE-insulated cables under electrical-thermal aging," Journal of Nanomaterials, vol. 2020, no. 1, pp. 1-13, 2020.

[3] Y. Ohki and N. Hirai, "Effects of the structure and insulation material of a cable on the ability of a location method by FDR," IEEE Transactions on Dielectrics and Electrical Insulation, vol. 23, no. 1, pp. 77-84, 2016.

[4] B. X. Du, X. X. Kong, J. Li, and M. Xiao, "High thermal conductivity insulation and sheathing materials for electric vehicle cable application," IEEE Transactions on Dielectrics and Electrical Insulation, vol. 26, no. 4, pp. 1363-1370, 2019.

[5] G. Parise, L. Martirano, L. Parise, L. Gugliermetti, and F. Nardecchia, "A life loss Tool for an optimal management in the operation of insulated LV power cables," IEEE Transactions on Industry Applications, vol. 55, no. 1, pp. 167-173, 2019.

[6] G. Callender, P. L. Lewin, J. A. Hunter, and P. Rapisarda, "Modeling partial discharge in a three-phase cable joint experiment with minimal adjustable parameters," IEEE Transactions on Dielectrics and Electrical Insulation, vol. 24, no. 1, pp. 279-287, 2017.

[7] A. Khamlichi, G. Donoso, F. Garnacho, G. Denche, A. Valero, and F. Alvarez, "Improved cable connection to mitigate 
transient enclosure voltages in $220-\mathrm{kV}$ gas-insulated substations," IEEE Transactions on Industry Applications, vol. 52, no. 1, pp. 562-569, 2016.

[8] H. Ren, L. Zhong, X. Yang et al., "Electric field distribution based on radial nonuniform conductivity in HVDC XLPE cable insulation," IEEE Transactions on Dielectrics and Electrical Insulation, vol. 27, no. 1, pp. 121-127, 2020.

[9] Y. Ohki and N. Hirai, "Detection of abnormality occurring over the whole cable length by frequency domain reflectometry," IEEE Transactions on Dielectrics and Electrical Insulation, vol. 25, no. 6, pp. 2467-2469, 2018.

[10] P. Cheetham, C. H. Kim, S. Pamidi, and L. Graber, "Optimization of a superconducting gas-insulated transmission line," IEEE Transactions on Dielectrics and Electrical Insulation, vol. 26, no. 3, pp. 930-938, 2019.

[11] L. S. Lakshmi, K. P. Thakur, and M. P. Staines, "Magnetic AC loss characteristics of $2 \mathrm{G}$ roebel cable," IEEE Transactions on Applied Superconductivity, vol. 19, no. 3, pp. 3361-3364, 2016.

[12] J. Zhang, Y. He, and W. Cui, "Reliability life prediction of smart meter based on multi-stress degradation model," Journal of Beijing University of Aeronautics and Astronautics, vol. 43, no. 8, pp. 1662-1669, 2017.

[13] Y. Ohki, "Development of an XLPE-insulated cable for LCCHVDC power lines (News from Japan)," IEEE Electrical Insulation Magazine, vol. 34, no. 4, pp. 62-65, 2018.

[14] A. P. Vikharev, "Electromagnetic situation near gas-insulated and cable power lines," Power Technology and Engineering, vol. 52, no. 2, pp. 223-226, 2018.

[15] H. Zhang, J. Zhang, L. Duan, S. Xie, and J. Xue, “Application status of XLPE insulated submarine cable used in offshore wind farm in China," Journal of Engineering, vol. 2017, no. 13, pp. 702-707, 2017.

[16] J. Snajdr, J. P. Bentley, R. Hauck, and P. Novak, "Stress on outer cable connection of MV gas-insulated switchgear due to cable thermal expansion at rated current," CIRED-Open Access Proceedings Journal, vol. 2017, no. 1, pp. 450-453, 2017.

[17] R. Benato, S. D. Sessa, L. Guizzo, and M. Rebolini, "Synergy of the future: high voltage insulated power cables and railwayhighway structures," IET Generation, Transmission \& Distribution, vol. 11, no. 10, pp. 2712-2720, 2017.

[18] G. A. Vinther, "Controlled-impedance cable termination with compensation for cable expansion and contraction," Clinical Trials, vol. 6, no. 1, pp. 76-89, 2016.

[19] B. Gustavsen, M. Hoyer-Hansen, P. Triverio, and U. R. Patel, "Inclusion of wire twisting effects in cable impedance calculations," IEEE Transactions on Power Delivery, vol. 31, no. 6, pp. 2520-2529, 2016.

[20] B. Zhang, J. Zou, and X. Du, "Ground admittance of an underground insulated conductor and its characteristic in lightning induced disturbance problems," IEEE Transactions on Electromagnetic Compatibility, vol. 59, no. 3, pp. 894-901, 2016.

[21] L. Boukezzi, L. Bessissa, A. Boubakeur, and D. Mahi, "Neural networks and fuzzy logic approaches to predict mechanical properties of XLPE insulation cables under thermal aging," Neural Computing \& Applications, vol. 28, no. 11, pp. 35573570, 2017.

[22] E. H. Doedens and E. M. Jarvid, "Considerations on the impact of material mesostructure on charge injection at cable interfaces," IEEE Electrical Insulation Magazine, vol. 36, no. 5, pp. 43-51, 2020.

[23] A. G. Shcherbinin and R. P. Lukoyanov, "Numerical studies of the electric field of a power cable with sector strands and impregnated paper-plastic insulation for a voltage of $20 \mathrm{kV}$,"
Russian Electrical Engineering, vol. 91, no. 11, pp. 698-702, 2020.

[24] C. Dang, J. Cote, and J. Tarnowski, "Emergency-temperature testing on MV jacketed reduced-wall TRXLPE aluminum cable systems in duct bank," IEEE Transactions on Power Delivery, vol. 33, no. 6, pp. 2894-2900, 2018. 